\title{
Effects of Insect Herbivory on Bilberry Production and Removal of Berries by Frugivores
}

\section{Koski, Tuuli-Marjaana}

2017-04

Koski , T-M , Kalpio, M , Laaksonen , T, Sirkiä , P , Kallio , H P , Yang , B , Linderborg , K M \& Klemola , T 2017 , ' Effects of Insect Herbivory on Bilberry Production and Removal of Berries by Frugivores ' , Journal of Chemical Ecology , vol. 43 , no. 4 , pp. 422-432 . https://doi.org/10.1007/s10886-

http://hdl.handle.net/10138/311754

https://doi.org/10.1007/s10886-017-0838-8

unspecified

acceptedVersion

Downloaded from Helda, University of Helsinki institutional repository.

This is an electronic reprint of the original article.

This reprint may differ from the original in pagination and typographic detail.

Please cite the original version. 


\section{EFFECTS OF INSECT HERBIVORY ON BILBERRY PRODUCTION AND REMOVAL OF BERRIES BY FRUGIVORES}

TUULI-MARJAANA KOSKI ${ }^{1}$ *, MARIKA KALPIO ${ }^{2}$, TONI LAAKSONEN ${ }^{1}$, PÄIVI M. SIRKIÄ ${ }^{1,3}$, HEIKKI P. KALLIO $^{2,4}$, BAORU YANG ${ }^{2}$, KAISA M. LINDERBORG ${ }^{2}$, TERO KLEMOLA ${ }^{1}$

${ }^{1}$ Section of Ecology, Department of Biology, University of Turku, FI-20014, Turku, Finland

${ }^{2}$ Section of Food Chemistry and Food Development, Department of Biochemistry, University of Turku, FI-20014, Turku, Finland

${ }^{3}$ Finnish Natural History Museum, Zoology Unit, University of Helsinki, FI-00014, Finland

${ }^{4}$ Centre for Environmental Research, Kevo Subarctic Research Institute, University of Turku, FI-20014, Turku, Finland

Corresponding author:

Tuuli-Marjaana Koski; tmhkos@utu.fi

Section of Ecology, Department of Biology, University of Turku, FI-20014, Turku, Finland

Tel. $+358(0) 407719168$ 
Abstract -The evolutionary purpose of a fleshy fruit is to attract seed dispersers and get the seeds dispersed by frugivorous animals. For this reason, fruits should be highly rewarding to these mutualists. However, insect herbivory can alter plant reproductive success e.g. by decreasing fruit yield or affecting the attractiveness of the fruits to mutualistic seed dispersers. Under natural conditions, we tested the effects of experimental larval-defoliation on berry ripening and consumption of a non-cultivated dwarf shrub, the bilberry (Vaccinium myrtillus L.), which produces animal-dispersed berries with high sugar and anthocyanin concentration. Bilberry ramets with high fruit yield were most likely to get their berries foraged, indicating that frugivores made foraging choices based on the abundance of berries. Moreover, the probability for berries being foraged was the lowest for non-defoliated ramets that grew adjacent to larval-defoliated ramets, even though larval-defoliation did not affect the biochemical composition (total concentrations of anthocyanins, sugars and organic acids) or the probability of ripening of berries. We hypothesise that the lower probability for berries being foraged in these ramets may be a consequence of rhizome- or volatile-mediated communication between ramets, resulting in a priming effect of the herbivore defence and lower attractiveness of the non-defoliated ramets.

Key Words - Tritrophic interactions, mutualism, herbivory, frugivory, foraging. 


\section{INTRODUCTION}

Since the evolutionary purpose of fleshy fruits is to attract seed dispersers and get the seeds dispersed by frugivorous animals, fruits should be highly rewarding to mutualistic dispersers. However, there is intraspecific variation e.g. in size (Pato and Obeso 2012; Wheelwright 1993) and number of fruits produced per plant (e.g. Jordano 1995), as well as in concentrations of sugars, anthocyanins and other nutrients in the fruits (Izhaki et al. 2002; Kalt et al. 1999; Levey 1987; Lätti et al. 2008; Schaefer and Braun 2009; Uleberg et al. 2012). Because seed dispersers should favour plants with most rewarding fruits, differences in quality or quantity of fruits can affect their attractiveness. For example, some frugivores favour large fruits over small or medium ones (e.g. Alcántara et al. 1997; van Lent et al. 2014; Wheelwright 1993) or plant individuals with large crop size (Alcántara et al. 1997; Blendinger et al. 2008; Christensen and Whitham 1991; Ortiz-Pulido et al. 2007; Pizo and Almeida-Neto 2009; Sallabanks 1993). Variation in the concentrations of sugars and acids can also affect attractiveness of fruits due to differences in taste. For example, some tanagers are able to detect very small differences in sugar concentration of the fruits (Levey 1987; Schaefer et al. 2003). Variation in anthocyanin content can also affect the attractiveness of fruits, because anthocyanins are not only pigments but also potent antioxidants (Schaefer et al. 2004; 2008; Tamura and Yamagami 1994; Wang et al. 1997; Zheng and Wang 2003), and their presence can indicate the presence of some colourless antioxidants (Schaefer et al. 2008; Zheng and Wang 2003). Indeed, some birds actively select anthocyanins, as well as other antioxidants and lipids in their diet and are able to discriminate between varying anthocyanin or lipid concentrations based on the colour of the fruit (Alan et al. 2013; Bolser et al. 2013; Catoni et al. 2008; Schaefer et al. 2008, 2014).

Because the differences in plant characteristics and frugivore preferences likely lead to differences in seed dispersal success, it is important to understand factors affecting fruit production and attractiveness of plants to frugivores. Abiotic (e.g. availability of water, nutrients and light) and genetic factors can affect the characteristics of flowers and fruits of plants. In addition, insect herbivory may affect plant fitness due to investments in defence, which can result in allocation or ecological costs (Bronstein et al. 2007; Heil 2002; Strauss et al. 2002). Herbivory may lower reproductive effort if the plant allocates resources to defence or regrowth, while investing fewer resources to reproduction. For example, several studies indicate that damage on vegetative tissue reduces the amount of resources invested in reproduction (Louda 1984; Marquis 1984; Pratt et al. 2005; Puentes and Ågren 2012; 
Treadwell and Cuda 2007; van Lent et al. 2014; Wise and Sacchi 1996, but see e.g. Oyama and Mendoza 1990). Herbivory may also lead to ecological costs e.g. due to pleiotropy, as induced defence against herbivory in vegetative tissues may result in accumulation of secondary metabolites also to reproductive tissues (Adler 2000; Adler et al. 2006; Eriksson and Ehrlén 1998; Irwin and Adler 2006; McArt et al. 2013), which may affect the foraging behaviour of seed dispersers. Whitehead and Poveda (2011) found that insect herbivory can have a negative impact on foraging choices of seed dispersing birds by affecting the palatability and developmental time of fruits in Hamelia patens Jacq. (Rubiaceae). In clonal plants, herbivory may potentially affect fruit production and fruit quality of several ramets (i.e. functionally autonomous clones) or the whole genet, because attack in one ramet can induce systemic resistance in other interconnected ramets (Chen et al. 2011; Gómez et al. 2007, 2010; Gómez and Stuefer 2006). Although the purpose of potentially unpalatable secondary metabolites in fleshy fruits and their possible effects on seed dispersers has long been of interest (reviewed in Cipollini and Levey 1997; Eriksson and Ehrlén 1998; Herrera 1982), the effects of herbivory on other biochemical characteristics, such as sugar or anthocyanin concentrations, are poorly known. However, removal of leaf tissue can negatively affect anthocyanin and sugar concentration as well as $\mathrm{pH}$ of fruits (Casierra-Posada et al. 2013; Pastore et al. 2013).

Despite the above-mentioned consequences that herbivory may inflict upon plant reproduction, we are not aware of studies that have simultaneously investigated the effects of insect herbivory on multiple reproductive aspects of fleshy fruiting plants, such as ripening, yield, and biochemical characteristics of fruits and foraging preferences of frugivores. Thus, using a non-cultivated clonal dwarf shrub, bilberry (Vaccinium myrtillus L.) and autumnal moth (Epirrita autumnata Borkhausen) larvae as study species in the field experiment, we tested the effects of insect herbivory on fruit ripening and nondefence related biochemical characteristics of berries while monitoring the removal of ripe fruits by mutualistic frugivores. We also analysed the profiles of anthocyanins, sugars and acids to confirm typical compounds of bilberries. However, we focus on their total concentrations, because birds can discriminate different anthocyanin and sugar concentrations (e.g. Bolser et al. 2013; Levey 1987; Schaefer et al. 2003, 2008), and because to our knowledge it is not known if some individual anthocyanins or sugars are especially attractive to birds. We hypothesised that possible trade-offs between induced herbivore defence and reproduction should be seen as either 1) allocation costs between defence and reproduction, observed 
as lowered probability for berries to ripen, or changed concentrations of anthocyanins, sugars and acids, together with 2) ecological costs, i.e. lowered probability of ripe berries to be removed from herbivoretreated plants by frugivorous birds.

\section{METHODS AND MATERIALS}

Species. Bilberry is a common perennial clonal shrub, with a distribution ranging from northern- to central Europe, often being a dominating species in spruce forests (Albert et al. 2003; Eriksson and Fröborg 1996; Miina et al. 2009; Ritchie 1956). In bilberry, a ramet is an orthotropic shoot that is connected to a belowground rhizome (i.e. horizontal stem) (Tolvanen and Laine 1997), and ramets belonging to the same clone tend to be closely associated due to phalanx growth strategy (Albert et al. 2003). Despite vegetative propagation, bilberry produces large amounts of sweet-tasting berries with high concentrations of anthocyanins (Kalt et al. 1999; Laaksonen et al. 2010; Ritchie 1956; Riihinen et al. 2008). These dark blue-black berries are consumed and dispersed by a large number of birds, such as grouses, partridges, thrushes and warblers, and by some mammals (Honkavaara et al. 2007; Pato and Obeso 2012; Ritchie 1956). Furthermore, the berries have a wax coating that reflects UV-light, which acts as a visual foraging cue for frugivorous birds (Siitari et al. 1999).

Autumnal moth was used as an herbivore species in the herbivory treatment, because it is a generalist that feeds also on bilberry (Silvonen et al. 2014). It has also been used as a defoliator in previous studies on bird foraging behaviour (Mäntylä et al. 2008a, b, 2014). The larvae from our breeding stock were reared on bilberry in laboratory conditions until they reached at least the $3^{\text {rd }}$ instar and were used in the experiment.

Field Experiment. The field experiment was launched in 20 forest blocks of ca. $100 \mathrm{~m}^{2}$ in mixed forest on the island of Ruissalo ( $\left.60^{\circ} 27^{\prime} \mathrm{N}, 22^{\circ} 16^{\prime} \mathrm{E}\right)$, Turku, southern Finland, in 2013 and 2014. There was ca. $50 \mathrm{~m}$ interval (minimum $10 \mathrm{~m}$ but no more than $1 \mathrm{~km}$ ) between the forest blocks. In each forest block, three control and three herbivore treatment plots (ca. 1-3 $\mathrm{m}^{2}$; Figure 1) were established. The minimum distance between the plots in a forest block was five meters. In each plot, two randomly chosen bilberry ramets were partially bagged with mesh bags (mesh $0.3 \mathrm{~mm}$ ), while another two ramets in the same plot 
were left without bags. To maximise the berry yield, we avoided bagging flowers and unripe berries with autumnal moth larvae, because although the larvae are leaf chewers, they can also feed on reproductive structures of bilberries when enclosed inside mesh bags (T.-M. K., personal observation). On average, 25 $\%$ of the ramet was covered, (min. ca. $10 \%$, max $50 \%$, depending on the size and architecture of a ramet). The distance between the four ramets in a plot was ca. 1.5 meters (ranging from ca. $0.5 \mathrm{~m}$ to $3 \mathrm{~m}$ ), which is close to the size of an average bilberry clone (Albert et al. 2003). In herbivore treatment plots, the mesh bags contained two to five autumnal moth larvae, while in control plots the mesh bags were empty. The non-bagged ramets in the herbivore treatment plots were expected to have rhizome or root connections to the neighbouring larval-defoliated ramets, because the ramets belonging to the same clone tend to be closely associated (Ritchie 1956; Albert et al. 2003). In addition, interconnected ramets likely induce systemic resistance upon insect herbivory (Chen et al. 2011; Gómez et al. 2007, 2010; Gómez and Stuefer 2006). Herbivore-damage can also lead to defence induction in neighbour intact plants via airborne signals (e.g. Engelberth et al. 2004; Karban et al. 2003). Consequently, the non-bagged ramets in the herbivore treatment plots were considered "rhizome signalling treatment". Because the mesh bags (while still allowing air flow) could potentially reduce evaporation or cause shading, the bagged ramets in control plots were considered methodological controls and the non-bagged ones controls. Thus, the bilberry ramets in herbivore treatment plots were 1) larval-defoliated or 2) in expected rhizome connection to larval-defoliated ramets, while the ramets in control plots were 3) methodological controls (bagged) or 4) (non-bagged) controls (Figure 1). In total, 477 ramets in 120 plots in 20 forest blocks were used when the two study years were combined. To ensure efficiency of the herbivore treatment, the larvae were allowed to feed from 7 to 21 days, after which the mesh bags were removed and the defoliation damage was visually estimated from the amount of chewing damage on the leaves and stem. The amount of chewing damage ranked from ca. $20 \%$ (the branch had some chewing damage but most of the leaves and stem were intact) to $100 \%$ (completely defoliated branch). The mean damage was $76.1 \%$ ( \pm SE 3.2$)$ in 2013 and $71.9( \pm$ SE 3.2) in 2014.

To ensure pollination without any disturbance, the experiment was established in late May- early June during late flowering when unripe berries were starting to form. The total number of flowers and unripe berries per ramet was counted (hereafter referred to as reproductive potential). The development of berries from flowers and unripe berries to ripe ones was surveyed 11-12 times (every two or three days) 
per ramet during the fruiting season. From these data, we calculated the total number of ripe berries produced per ramet and how many of the ripe berries disappeared during the surveillance, interpreted as eaten by birds (hereafter referred to as foraged berries). During the surveillance, birds (mostly fieldfares Turdus pilaris L. and blackbirds Turdus merula L.) were seen feeding on the ripe berries but no direct quantitative data on avian foraging behaviour were collected. In mid-July samples of ripe berries were collected for biochemical analysis (two ramets per plot: one bagged and one without a bag) from each plot of all forest blocks. Since the berries (both within and between ramets) ripened asynchronously, the berry samples were collected twice (ca. one week apart) from each ramet. The samples were combined according to treatment and forest block: each treatment group in a particular forest block formed an individual sample. In total, 37 samples from year 2013 and 40 samples from year 2014 were analysed. The samples were stored at $-20^{\circ} \mathrm{C}$ and analysed in a random order (see below).

\section{Biochemical Analyses.}

Total Anthocyanins. The total content of anthocyanins (mg/g of dry weight, DW) was determined by spectrophotometer as cyanidin-3-O-galactoside (Extrasynthese, Genay, France) equivalents at $530 \mathrm{~nm}$. The anthocyanins were extracted as previously described (Zheng et al. 2012). In total, $5 \mathrm{~mL}$ of $\mathrm{MeOH}: \mathrm{HCl}$ (99:1) was added to ca. $40 \mathrm{mg}$ of freeze-dried bilberry sample and mixed with Vortex for two minutes followed by centrifuging for $10 \mathrm{~min}$ at $3400 \times \mathrm{g}$. The efficiency of extraction was tested by four consecutive extractions of three parallel samples, and the correction factors for two extracts were calculated. Absorbance of the diluted samples was determined spectrophotometrically using Ultrospec $7000 \mathrm{UV} /$ visible spectrophotometer at $530 \mathrm{~nm}$, and the $100 \%$ yield was calculated as previously described (Sandell et al. 2009). In final analyses, each sample was extracted twice, absorbance of both diluted samples was determined and the $100 \%$ recovery calculated as above. The total concentrations of anthocyanins were calculated based on five-point external standard curves $\left(R^{2}>0.99\right.$, Figure $S 1$ in the Supplementary material) of cyanidin-3-O-galactoside.

UHPLC-DAD Analysis of Anthocyanins. The anthocyanin profiles were determined with ultrahigh performance liquid chromatograph with diode array detector (UHPLC-DAD) Shimadzu Nexera and Prominence LC system (Kyoto, Japan) consisted of a SIL-30AC autosampler, LC-30AD pumps, a CTO20AC column oven, and a DGU-20A5 degasser. Prior to LC analysis, the samples were filtered through a 
$0.45 \mu \mathrm{m}$ syringe filter. Anthocyanins were separated at $25{ }^{\circ} \mathrm{C}$ (flow rate according to Lätti et al. 2008) using a Kinetex C18 column $(2.6 \mu \mathrm{m}, 100 \times 4.60 \mathrm{~mm}$, Phenomenex, Torrance, CA). UV spectra were recorded from 200 to $700 \mathrm{~nm}$, and anthocyanins were detected at $520 \mathrm{~nm}$ with a SPD-M20A DAD. In chromatographic separation, $5 \%$ formic acid v/v in ultra-pure water (A) and acetonitrile (B) were used as solvents according to the modified gradient program of Lätti et al. (2008). Acetonitrile, methanol, hydrochloric acid and formic acid were of HPLC grade or of the highest purity available. The most common anthocyanins of bilberries were identified based on the UV-Vis spectra and literature (Laaksonen et al. 2010). The proportions of individual anthocyanins in each sample were defined by their shares in the HPLC chromatograms. Based on this information, the contents of each anthocyanin (mg/g DW) in all samples were calculated.

GC-FID Analyses of Sugars and Organic Acids. Concentrations of sugars and organic acids were analysed by using gas chromatograph with flame ionization detector (GC-FID). On average, $70 \mathrm{mg}$ of freeze-dried bilberries were extracted with $3 \mathrm{~mL}$ of ultra-pure water, vortexed for $2 \mathrm{~min}$, sonicated for 30 min and centrifuged $1000 \times \mathrm{g}$ for $5 \mathrm{~min}$. For three parallel samples the extraction procedure was repeated three times, and correction factors for $100 \%$ yield were calculated. In addition, compound-specific correction factors were determined based on the analyses of pure reference compounds (Table 1). Internal standards, sorbitol for sugars and tartaric acid for acids, were added to the aliquot of $1 \mathrm{~mL}$ of bilberry extracts. A portion of $300 \mu \mathrm{L}$ of the filtrated $(0.45 \mu \mathrm{m})$ samples were evaporated to dryness under nitrogen flow and kept in a desiccator until analysed. Trimethylsilyl (TMS) derivatives were prepared by adding Tri-Sil HTP reagent (HMDS:TMCS:pyridine, 2:1:10, Thermo Scientific, Pierce Biotechnology, Rockford, IL), shaking vigorously, and incubating for $30 \mathrm{~min}$ at $60^{\circ} \mathrm{C}$ (Tiitinen et al. 2006).

The gas chromatographic analysis of TMS derivatives of sugars and organic acids was carried out using Shimadzu GC-2010Plus equipped with Autoinjector-20i / Autosampler AOC-20s and a flame ionization detector (Shimadzu Corp., Kyoto, Japan). Helium was used as the carrier gas with a flow rate $1.4 \mathrm{~mL} / \mathrm{min}$. A non-polar capillary column $\mathrm{SPB}^{\mathrm{TM}}-1(30 \mathrm{~m} \times 0.25 \mathrm{~mm}$, liquid film $0.25 \mu \mathrm{m}$, Supelco, Bellefonte, PA) was used for separation of the TMS derivatives. The split ratio was 1:15. The temperatures of the injector and the detector were $210{ }^{\circ} \mathrm{C}$ and $290{ }^{\circ} \mathrm{C}$, respectively. The column oven was programmed to hold $150{ }^{\circ} \mathrm{C}$ for $2 \mathrm{~min}$, increase to $210{ }^{\circ} \mathrm{C}$ at $4{ }^{\circ} \mathrm{C} / \mathrm{min}$, and finally to increase to $275^{\circ} \mathrm{C}$ at $40{ }^{\circ} \mathrm{C} / \mathrm{min}$ and to hold for $5 \mathrm{~min}$. The peaks of the TMS derivatives of sugars and acids were identified by 
comparing their retention times with the retention times of external standards. Quantifications (mg/g DW) were made in relation of area to that of the internal standards.

\section{Statistical Analysis.}

Development of Berries and Removal of Ripe Berries by Frugivores. From the surveillance data of berry development, we calculated the total number of ripened berries in relation to the reproductive potential in the beginning of the experiment. We also calculated the total number of foraged ripe berries in relation to total number of ripe berries that were available for birds, i.e. excluding the ripe berries that were collected for biochemical analyses, and the ones that dried out or were unintentionally detached. It was noticed in a few cases that approximately half of the volume of a berry was destroyed by wild, fruit-boring insect larvae, but despite this the bilberries often still ripened (T-M Koski, personal observation). These berries were nevertheless not included in the total number of ripened berries because they were likely to be avoided by frugivorous birds (Traveset et al. 1995) and to dry out.

Using the GLIMMIX procedure of the SAS (v. 9.4) statistical software, the probability of ripening was analysed with a generalized linear mixed model (GLMM) with binomial error distribution and logit link function. For the response variable, we used the events/trial syntax, where events were the total number of ripened berries and trials were the reproductive potential. Year (2013 or 2014), treatment nested within plot type (with or without larvae), plot type and their pairwise interactions were set as independent variables. The treatment was nested within plot type to take into account that each plot type contained only two treatment levels (larval-defoliation and rhizome signalling in one plot type and control and methodological control in another plot type). Spatial non-independencies of observations were controlled for by setting forest block, plot nested within forest block, and an individual ramet nested within a plot as random effects. The probability of an individual berry to be foraged by frugivores was analysed with similar events/trial analysis, where events were the total number of foraged berries and trials were the total number of berries available for birds in a ramet. In this analysis, the total number of ripened berries in a ramet was included as a covariate. Because the pairwise interactions between the covariate and other independent variables were not significant, they were left out of the model. The Kenward-Roger method (latest version, Kenward and Roger 2009) was used to compute the denominator degrees of freedom for all models. 
Total Concentrations of Anthocyanins, Sugars and Organic Acids. To meet normality and homoscedasticity assumptions of the residual distribution, the total concentration (mg/g DW) of anthocyanins was analysed by a GLMM with lognormal error distribution and identity link function, while the total concentrations of sugars and acids were analysed with normal error distribution and identity link function. The independent variables were the same as in the analyses of the ripening data. Forest block was set as random effect in all biochemical analyses to control for spatial non-independence of the samples. In addition, although the main interest in this study was in the total concentrations, similar analyses were conducted for the concentrations (mg/g DW) of individual anthocyanin, sugar and acid compounds (with normal or lognormal distribution and identity link function, see Supplementary material Table S1). Due to low concentrations of sucrose and xylose, the concentrations of these compounds were analysed together.

\section{RESULTS}

There was no difference in the reproductive potential between treatments or plot types in the beginning of the experiment in 2013 (GLMM on count data with negative binomial error distribution: treatment nested within plot type: $F_{2,181.9}=1.63, P=0.20$; plot type: $\left.F_{1,48.86}=0.89, P=0.35\right)$ or in $2014\left(F_{2,181.4}=1.76\right.$, $P=0.18 ; F_{1,48.13}=0.37, P=0.54$, respectively).

There was an interaction effect between treatment and year on the probability of ripening of the berries (Table 2). Methodological control ramets had the highest ripening probability in 2013 but differences in the ripening probability between treatments were not found in 2014 (Figure 2). In addition, the probability of ripening was very low, especially in non-bagged ramets, in 2013 compared to 2014 (Figure 2).

There was a significant difference among treatments (nested within plot type) in the foraging probability of ripe berries by frugivores (Table 3). Rhizome signalling ramets were least likely to get their berries foraged (Figure 3). Furthermore, the total number of berries in a ramet, [estimate in logit scale 0.013 (95\% CI: 0.001 to 0.024 )] significantly affected the foraging probability (Table 3): ramets with high fruit yield were most likely to get their berries foraged independently of the treatment level.

Treatment or its interaction with year did not have any significant effects on total concentrations of anthocyanins, sugars or organic acids (Table 4). The total concentrations for anthocyanins, sugars and 
acids in each treatment are given in Table 5. In these analyses, only the year by plot type interaction was significant on sugars: the berries in control plots of 2013 had lower sugar concentration compared to other factor combinations (Figure 4). Example profiles of HPLC-DAD of the anthocyanins and GC-FID of the TMS derivatives of sugars and acids are presented in Supplementary material Figure S2 a and b, respectively. The proportions of individual anthocyanin, sugar and acid compounds (mg/g DW) in each treatment are presented as in Figure S3 a, b and c.

None of the explanatory variables had significant effects on the concentration of individual anthocyanins (Table S1). However, year and its interaction with plot type affected concentration of glucose (Table S1), and similarly year by plot type interaction affected the concentration of quinic acid (Table S1): berries collected from control plots in 2013 had the lowest glucose and highest quinic acid concentration compared to other factor combinations (Figure S4 a and b). Year, treatment, their pairwise interaction, and year by plot type interaction had significant effect on the summed concentration of sucrose and xylose (Table S1): berries from defoliated ramets in 2014 had lower concentration of sucrose and xylose compared to other treatments in 2014 (Figure S5). Concentration of malic acid was significantly lower in 2013 [back transformed values from log scale: mean 14.2 (95\% CI: 10.9 to 18.5 ) mg/g DW] compared to 2014 [mean 21.7 (95\% CI: 16.9 to 27.9) mg/g DW].

\section{DISCUSSION}

We tested whether larval-defoliation influences resource allocation in bilberry, measured as the ripening probability of berries and their biochemical composition. We also tested whether herbivory causes an ecological cost to bilberry by affecting the attractiveness of the berries to frugivores, measured as the probability for berries to be foraged. The size of fruit yield significantly affected the probability of berries being foraged: berries in ramets with high fruit yield had higher probability to be foraged compared to berries in ramets with lower fruit yield. This is in accordance with previous studies, indicating that birds prefer plants with high fruit yield (Blendinger et al. 2008; Ortiz-Pulido et al. 2007; Sallabanks 1993). By visiting plants with high fruit yield a frugivore likely minimizes search and travel time while maximizes foraging efficiency (Martin 1985; Sallabanks 1993). Large fruit displays may also be more detectable due to higher conspicuousness (Denslow et al. 1986; Howe and Estabrook 1977; Sallabanks 1993). For example, Schmidt et al. (2004) suggested that conspicuousness of fruits is an important foraging cue for 
frugivorous birds because birds prefer fruits with high contrast against their background. Furthermore, berries that reflect UV light, such as bilberry, may be especially conspicuous against leaves, as leaves strongly absorb UV irradiance while effectively reflecting green light (Altshuler 2001).

In addition to fruit yield, the herbivory treatment indirectly affected the probability for berries to be foraged. Rhizome signalling ramets were least-favoured by seed-dispersers (Figure 3, Table 3). Bilberry ramets belonging to a same clone tend to be closely associated (Albert et al. 2003), and interconnected ramets are likely able to induce systemic resistance upon insect herbivory (Chen et al. 2011; Gómez et al. 2007, 2010; Gómez and Stuefer 2006). For these reasons, we suspect that the ramets in a same plot were likely rhizome-connected, which enabled the priming effect in the non-defoliated ramets in herbivore treatment plots. It is also possible that the ramets neighbouring larval-defoliated ramets may have responded to a release of herbivore-induced volatile organic compounds (HI-VOCs) from defoliated ramets. Volatile mediated plant-plant signalling has been identified in several plant species (e.g. Engelberth et al. 2004; Karban et al. 2003; Ton et al. 2007), and a closely related species, the highbush blueberry (Vaccinium corymbosum L.) uses HI-VOCs to prime itself against herbivore attack (Rodriguez-Saona et al. 2009). Regardless of the potential defence signalling mechanism between ramets, priming may have affected the attractiveness of berries e.g. by affecting their conspicuousness. Systemic defence induction has been shown to reduce light reflectance and/or photosynthetic activity of leaves in some plants (Amo et al. 2013; Mäntylä et al. 2008 a,b; Zangerl et al. 2002; ), which likely changes the contrasts of berries against leaves. In addition, induced defence response may also affect palatability of fruits and alter the attractiveness of the plants to mutualistic birds (Whitehead \& Poveda 2011). However, Forst et al. (2008) concluded that even though priming is expected to be less costly than direct induction of defence chemicals, costs of priming in the context of plant-herbivore interactions and how long the primed stage can last, are poorly known issues. Further studies about the mechanism on how herbivory affects neighbouring ramets in bilberry and how this affects foraging preferences of frugivores, are needed to confirm our ramet-ramet signalling and defence-induction hypotheses.

Despite the difference in the probability of berries to be foraged, we did not find an allocation cost between defence and reproduction as larval-defoliation did not significantly affect the probability of ripening. This was unexpected, as accumulation of sugars, water, pigments and other resources to berries during ripening likely demands resources. This is also in contrast with some previous studies where 
allocation costs between vegetative damage and reproduction have been found (e.g. Koptur et al. 1996; Obeso 1993; Thalmann et al. 2003). Contrariwise, Obeso and Grubb (1993) did not find effects of defoliation on fruit production of Ligustrum vulgare (L). Similarly, larval-defoliation did not affect seed production of horse chestnut trees (Aesculus hippocastanum L.), although seed weight was affected (Thalmann et al. 2003). In case of bilberry, it is possible that storages in roots or rhizomes may have been able to compensate the resource loss caused by herbivory. Roots and rhizomatous tissue can act as storages for e.g. nitrogen and carbohydrates and some clonal plants transport resources between interconnected ramets (Alpert 1991; Evans 1992; Kaur et al. 2012; Loescher et al. 1990; Lähdesmäki et al. 1990), and this resource storage and transport possibility in bilberry has also been discussed in some previous studies (Tolvanen 1994; Tolvanen et al. 1994; Tolvanen and Laine 1997). Alternatively, plants may have increased their photosynthetic capacity, because according to Tolvanen and Laine (1997), bilberry responses to vegetative damage by allocating resources to growth. In addition, previous studies also suggest that bilberry likely is moderately tolerant to vegetative damage (Tolvanen 1994; Tolvanen et al. 1994; Tolvanen and Laine 1997).

Larval-defoliation also did not affected the total concentrations of anthocyanins, sugars, or organic acids (Table 4), even though their composition and/ or total concentrations can be affected by environmental factors, such as temperature, light and removal of leaves, despite the strong genetic control (Casierra-Posada et al. 2013; Castellarin et al. 2006; Etienne et al. 2013; Léchaudel et al. 2005; Lätti et al. 2008; Pastore et al. 2013; Uleberg et al. 2012; Wang and Camp 2000; Åkerström et al. 2010). For example, Casiera-Posada et al. (2013) showed that defoliation can decrease the concentration of sugars and increase acidity in the strawberry (Fragaria $\times$ ananassa Duch. cv. Chandler). The concentrations of anthocyanins, sugars and acids in different treatments (Table 5) were similar to previously reported concentrations found in bilberry (Laaksonen et al. 2010; Lätti et al. 2008; Mikulic-Petkovsek et al. 2012; Uleberg et al. 2012). In addition, the profiles of anthocyanins, sugars and acids were in accordance with previous studies (Figure S2 a, b) (Laaksonen et al. 2010; Lätti et al. 2008). The only between-treatment difference in the total concentrations was measured for the total sugar concentration, which was the lowest in control plots in 2013 compared to other year by plot type combinations (Table 4, Figure 4). This likely resulted from having lower glucose concentrations (Figure S4 a), and higher quinic acid concentration (Figure S4 b) in these plots. There was also lower summed concentration of sucrose and 
xylose in berries collected from defoliated ramets in 2014 compared to other treatments in that year (Figure S5). The concentration of malic acid was almost twice as high in 2014 compared to 2013. Nevertheless, these differences in the biochemical composition of berries did not affect the foraging preferences of the frugivores (Table 3). Thus, the measured total concentrations of these three metabolite groups (or individual compounds tested) do not explain why ramets neighbouring larval-defoliated ramets were less foraged compared to other treatments.

The results both from the ripening and chemical data indicate that herbivory at early reproductive state (presence of flowers and unripe berries) does not significantly reduce resources from the developmental process of berries in bilberry. This is in contrast with some previous findings showing negative effect of vegetative damage on fruit production or their chemical composition (Casierra-Posada et al. 2013; Hegland et al. 2005; Koptur et al. 1996; Obeso 1993; Pastore et al. 2013; Thalmann et al. 2003). However, our result is similar to findings by Primack and Hall (1990), where the pink lady's slipper orchids (Cypripedium acaule Aiton) were able to mature their fruits despite defoliation, as well as Obeso and Grubb (1993) where defoliation did not affect fruit production during the year of damage. The reason for lack of effect of herbivory in the ripening process in bilberry may be that resource storages in rhizomes, or e.g. increase in photosynthetic biomass may have compensated the resource loss caused by larval-defoliation. It would be interesting to test how long-term and severe insect-herbivory (such as geometrid outbreak) affects the development of berries and their composition. For example, Tolvanen et al. (1993) found that the vegetative damage (removal of part of the ramet) decreased flowering in the following year, resulting in fewer ripened berries in the bilberry. Consequently, experiments investigating the effect of herbivory on the ramet-ramet signalling are needed to fully understand the physiological effects of herbivory on bilberry.

To conclude, our results indicate that attraction of frugivores to bilberry is partly dependent on the size of fruit yield, since frugivores favour ramets with large fruit yield. In contrast to some previous studies where ecological costs between herbivore defence and reproduction have been found (e.g. Whitehead and Poveda 2011) herbivory did not affect fruit removal in the larval-defoliated ramets. However, our results suggest that herbivory may lower removal and dispersion of berries by frugivores from the undamaged neighbouring ramets. In terms of ripening probability and total concentrations of anthocyanins, sugars and organic acids, herbivory does not significantly reduce resources from the 
ripening process of berries during that season. To increase understanding of this tritrophic interaction and to confirm the ramet-ramet signalling and defence-induction hypotheses, future studies should investigate the signalling mechanism between neighbouring ramets and how severity and frequency of insectdefoliation affects the development and chemical composition of berries and foraging preferences of frugivores.

Acknowledgements. We thank Turku University foundation (T. K), University of Turku research grant fund (T-M. K.), Academy of Finland (T. L. \& P.M. S.) and University of Turku Graduate School (T.-M. K.) for funding this experiment. We are grateful to Teija Luotohaara and Aino Tarkkio for their help with the biochemical analysis of berries and Ina-Sabrina Tirri, Jenni Poutanen, Matias Ukkola, Hanna Kalliolevo and Tuija Koivisto for their help in the field experiment.

\section{CONFLICT OF INTEREST}

The authors declare that they have no conflict of interest.

\section{REFERENCES}

Adler LS (2000) The ecological significance of toxic nectar. Oikos 91:409-420

Adler LS, Wink M, Distl M, Lentz AJ (2006) Leaf herbivory and nutrients increase nectar alkaloids. Ecol Lett 9:960 $-967$

Alan RR, McWilliams SR, McGraw KJ (2013) The importance of antioxidants for avian fruit selection during autumn migration. Wilson J Ornithol 125:513-525

Albert T, Raspé O, Jacquemart AL (2003) Clonal structure in Vaccinium myrtillus L. revealed by RAPD and AFLP markers. Int J Plant Sci 164:649-655

Alcántara JM, Rey PJ, Valera F, SánchezLafuente AM, Gutierrez JE (1997) Habitat alteration and plant intraspecific competition for seed dispersers. An example with Olea europaea var. sylvestris. Oikos 79:291-300

Alpert P (1991) Nitrogen sharing among ramets increases clonal growth in Fragaria chiloensis. Ecology 72:69-80

Altshuler DL (2001) Ultraviolet reflectance in fruits, ambient light composition and fruit removal in a tropical forest. Evol Ecol Res 3:767-778

Amo L, Jansen JJ, van Dam NM, Dicke M, Visser ME (2013) Birds exploit herbivore-induced plant volatiles to locate herbivorous prey. Ecol Lett 16:1348-1355

Blendinger PG, Loiselle BA, Blake JG (2008) Crop size, plant aggregation, and microhabitat type affect fruit removal by birds from individual melastome plants in the Upper Amazon. Oecologia 158:273-283

Bolser JA, Alan RR, Smith AD, Li LY, Seeram NP, McWilliams SR (2013) Birds select fruits with more anthocyanins and phenolic compounds during autumn migration. Wilson J Ornithol 125:97-108

Bronstein JL, Huxman TE, Davidowitz G (2007) Plant-mediated effects linking herbivory and pollination. Ecological Communities: Plant Mediation in Indirect Interaction Webs pp. 79-103. doi:10.1017/CBO9780511542701.005

Casierra-Posada F, Torres ID, Blanke MM (2013) Fruit quality and yield in partially defoliated strawberry plants in the tropical highlands. Gesunde Pflanz 65:107-112 
Castellarin SD, Di Gaspero G, Marconi R, Nonis A, Peterlunger E, Paillard S, Adam-Blondon AF, Testolin R (2006) Colour variation in red grapevines (Vitis vinifera L.): genomic organisation, expression of flavonoid 3 '-hydroxylase, flavonoid 3 ',5 '-hydroxylase genes and related metabolite profiling of red cyanidin-/blue delphinidin-based anthocyanins in berry skin. Bmc Genomics 7:12-17

Catoni C, Schaefer HM, Peters A (2008) Fruit for health: the effect of flavonoids on humoral immune response and food selection in a frugivorous bird. Funct Ecol 22:649-654

Chen JS, Lei NF, Liu Q (2011) Defense signaling among interconnected ramets of a rhizomatous clonal plant, induced by jasmonic-acid application. Acta Oecol 37:355-360

Christensen KM, Whitham TG (1991) Indirect herbivore mediation of avian seed dispersal in Pinyo pine. Ecology 72:534-542

Cipollini ML, Levey DJ (1997) Secondary metabolites of fleshy vertebrate-dispersed fruits: Adaptive hypotheses and implications for seed dispersal. Am Nat 150:346-372

Denslow JS, Moermond TC, Levey DJ (1986) Spatial components of fruit display in understory trees and shrub. In: Estrada A, Fleming TH (eds) Frugivores and seed dispersal. Dr.W. Junk, Boston, Massachusetts, USA, pp 37-44

Engelberth J, Alborn HT, Schmelz EA, Tumlinson JH (2004) Airborne signals prime plants against insect herbivore attack. P Natl Acad Sci USA 101:1781-785

Eriksson O, Ehrlén J (1998) Secondary metabolites in fleshy fruits: are adaptive explanations needed? Am Nat 152:905-907

Eriksson O, Fröborg H (1996) "Windows of opportunity" for recruitment in long-lived clonal plants: Experimental studies of seedling establishment in Vaccinium shrubs. Can J Bot 74:1369-1374

Etienne A, Génard M, Lobit P, Mbeguié-A-Mbéguié D, Bugaud C (2013) What controls fleshy fruit acidity? A review of malate and citrate accumulation in fruit cells. J Exp Bot. doi:10.1093/jxb/ert035

Evans JP (1992) The effect of local resource availability and clonal integration on ramet functional morphology in Hydrocotyle bonariensis. Oecologia 89:265-276

Frost CJ, Mescher MC, Carlson JE, De Moraes CM (2008) Plant defense priming against herbivores: Getting ready for a different battle. Plant Physiol 146:818-824

Gómez S, Latzel V, Verhulst YM, Stuefer JF (2007) Costs and benefits of induced resistance in a clonal plant network. Oecologia 153:921-930

Gómez S, Stuefer JF (2006) Members only: induced systemic resistance to herbivory in a clonal plant network. Oecologia 147:461-468

Gómez S, van Dijk W, Stuefer JF (2010) Timing of induced resistance in a clonal plant network. Plant Biol 12:512517

Hegland SJ, Rydgren K, Seldal T (2005) The response of Vaccinium myrtillus to variations in grazing intensity in a Scandinavian pine forest on the island of Svanøy. Can J Bot 83: 1638-1644

Heil M (2002) Ecological costs of induced resistance. Curr Opin Plant Biol 5: 345-350

Herrera CM (1982) Defense of ripe fruit from pests - its significance in relation to plant-disperser interactions. Am Nat 120:218-241

Honkavaara J, Siitari H, Saloranta V, Viitala J (2007) Avian seed ingestion changes germination patterns of bilberry, Vaccinium myrtillus. Ann Bot Fenn 44:8 -17

Howe HF, Estabrook GF (1977) Intraspecific competition for avian dispersers in tropical trees. Am Nat 111:817832

Irwin RE, Adler LS (2006) Correlations among traits associated with herbivore resistance and pollination: Implications for pollination and nectar robbing in a distylous plant. Am J Bot 93:64-72

Izhaki I, Tsahar E, Paluy I, Friedman J (2002) Within population variation and interrelationships between morphology, nutritional content, and secondary compounds of Rhamnus alaternus fruits. New Phytol 156:217-223

Jordano P (1995) Frugivore-mediated selection on fruit and seed size - birds and St Lucies cherry, Prunus mahaleb. Ecology 76:2627-2639

Kalt W, McDonald JE, Ricker RD, Lu X (1999) Anthocyanin content and profile within and among blueberry species. Can J Plant Sci 79:617-623

Karban R, Maron J, Felton GW, Ervin G, Eichenseer H (2003) Herbivore damage to sagebrush induces resistance in wild tobacco: evidence for eavesdropping between plants. Oikos 100:325-332 
Kaur J, Percival D, Hainstock LJ, Privé JP (2012) Seasonal growth dynamics and carbon allocation of the wild blueberry plant (Vaccinium angustifolium Ait.). Can J Plant Sci 92:1145-1154

Kenward MG, Roger JH (2009) An improved approximation to the precision of fixed effects from restricted maximum likelihood. Comput Stat Data An 53:2583-2595

Koptur S, Smith CL, Lawton JH (1996) Effects of artificial defoliation on reproductive allocation in the common vetch, Vicia sativa (Fabaceae: Papilionoideae). Am J Bot 83:886-889

Laaksonen O, Sandell M, Kallio H (2010) Chemical factors contributing to orosensory profiles of bilberry (Vaccinium myrtillus) fractions. Eur Food Res Technol 231:271-285

Levey DJ (1987) Sugar-tasting ability and fruit selection in tropical fruit-eating birds. Auk 104:173-179

Loescher WH, McCamant T, Keller JD (1990) Carbohydrate reserves, translocation and storage in woody plantroots. Hortscience 25:274-281

Louda SM (1984) Herbivore effect on stature, fruiting and leaf dynamics of a native crucifer. Ecology 65:13791386

Lähdesmäki P, Pakonen T, Saari E, Laine K, Tasanen L, Havas P (1990) Changes in total nitrogen, protein, aminoacids and $\mathrm{NH}_{4}+$ in tissues of bilberry, Vaccinium myrtillus, during the growing season. Holarctic Ecology 13:31-38

Lätti AK, Riihinen KR, Kainulainen PS (2008) Analysis of anthocyanin variation in wild populations of bilberry (Vaccinium myrtillus L.) in Finland. J Agr Food Chem 56:190-196

Léchaudel M, Joas J, Caro Y, Génard M, Jannoyer M (2005) Leaf : fruit ratio and irrigation supply affect seasonal changes in minerals, organic acids and sugars of mango fruit. J Sci Food Agr 85:251-260

Marquis RJ (1984) Leaf herbivores decrease fitness of a tropical plant. Science 226:537-539

Martin TE (1985) Resource selection by tropical frugivorous birds - integrating multiple interactions. Oecologia 66:563-573

McArt SH, Halitschke R, Salminen JP, Thaler JS (2013) Leaf herbivory increases plant fitness via induced resistance to seed predators. Ecology 94:966-975

Miina J, Hotanen JP, Salo K (2009) Modelling the abundance and temporal variation in the production of bilberry (Vaccinium myrtillus L.) in Finnish mineral soil forests. Silva Fenn 43:577-593

Mikulic-Petkovsek M, Schmitzer V, Slatnar A, Stampar F, Veberic R (2012) Composition of sugars, organic acids, and total phenolics in 25 wild or cultivated berry species. J Food Sci 77:C1064-C1070

Mäntylä E, Alessio GA, Blande JD, Heijari J, Holopainen JK, Laaksonen T, Piirtola P, Klemola T (2008a) From plants to birds: higher avian predation rates in trees responding to insect herbivory. PLoS ONE 3:e2832. doi: 10.1371/journal.pone.0002832

Mäntylä E, Blande JD, Klemola T (2014) Does application of methyl jasmonate to birch mimic herbivory and attract insectivorous birds in nature? Arthropod-Plant Inte 8:143-153

Mäntylä E, Klemola T, Sirkiä P, Laaksonen T (2008b) Low light reflectance may explain the attraction of birds to defoliated trees. Behav Ecol 19:325-330

Obeso JR (1993) Selective fruit and seed maturation in Asphodelus albus Miller (Liliaceae). Oecologia 93: 564-570

Obeso JR, Grubb PJ (1993) Fruit maturation in the shrub Ligustrum vulgare (Oleaceae)- lack of defolation effects. Oikos 68: 309-316

Ortiz-Pulido R, Albores-Barajas YV, Díaz SA (2007) Fruit removal efficiency and success: influence of crop size in a neotropical treelet. Plant Ecol189:147-154

Oyama K, Mendoza A (1990) Effect of defoliation on growth, reproduction, and survival of a neotropical dioecious palm, Chamaedorea tepejilote. Biotropica 22:119-123

Pastore C, Zenoni S, Fasoli M, Pezzotti M, Tornielli GB, Filippetti I (2013) Selective defoliation affects plant growth, fruit transcriptional ripening program and flavonoid metabolism in grapevine. Bmc Plant Biol $13: 30-45$

Pato J, Obeso JR (2012) Fruit mass variability in Vaccinium myrtillus as a response to altitude, simulated herbivory and nutrient availability. Basic Appl Ecol 13:338-346

Pizo MA, Almeida-Neto M (2009) Determinants of fruit removal in Geonoma pauciflora, an understory palm of neotropical forests. Ecol Res 24:1179-1186

Pratt PD, Rayamajhi MB, Van TK, Center TD, Tipping PW (2005) Herbivory alters resource allocation and compensation in the invasive tree Melaleuca quinquenervia. Ecol Entomol 30:316-326

Primack RB, Hall P (1990) Cost of reproduction in the pink lady's slipper orchid : a four-year experimental study. Am Nat 136: 638-656 
Puentes A, Ågren J (2012) Additive and non-additive effects of simulated leaf and inflorescence damage on survival, growth and reproduction of the perennial herb Arabidopsis lyrata. Oecologia 169:1033-1042

Riihinen K, Jaakola L, Kärenlampi S, Hohtola A (2008) Organ-specific distribution of phenolic compounds in bilberry (Vaccinium myrtillus) and 'northblue' blueberry (Vaccinium corymbosum x V angustifolium). Food Chem 110:156-160

Ritchie JC (1956) Vaccinium myrtillus L. J Ecol 44:291-299

Rodriguez-Saona CR, Rodriguez-Saona LE, Frost CJ (2009) Herbivore-induced volatiles in the perennial shrub, Vaccinium corymbosum, and their role in inter-branch signalling. J Chem Ecol 35:163-175

Sallabanks R (1993) Hierarchical mechanisms of fruit selection by an avian frugivore. Ecology 74:1326-1336

Sandell M, Laaksonen O, Järvinen R, Rostiala N, Pohjanheimo T, Tiitinen K, Kallio H (2009) Orosensory profiles and chemical composition of black currant (Ribes nigrum) juice and fractions of press residue. J Agr Food Chem 57:3718-3728

Schaefer HM, Braun J (2009) Reliable cues and signals of fruit quality are contingent on the habitat in black elder (Sambucus nigra). Ecology 90:1564-1573

Schaefer HM, McGraw K, Catoni C (2008) Birds use fruit colour as honest signal of dietary antioxidant rewards. Funct Ecol 22:303-310

Schaefer HM, Schaefer V, Levey DJ (2004) How plant-animal interactions signal new insights in communication. Trends Ecol Evol 19:577-584

Schaefer HM, Schmidt V, Bairlein F (2003) Discrimination abilities for nutrients: which difference matters for choosy birds and why? Anim Behav 65:531-541

Schaefer HM, Valido A, Jordano P (2014) Birds see the true colours of fruits to live off the fat of the land. P Roy Soc B-Biol Sci 281:7, doi: 10.1098/rspb.2013.2516

Schmidt V, Schaefer HM, Winkler H (2004) Conspicuousness, not colour as foraging cue in plant-animal signalling. Oikos 106:551-557

Siitari H, Honkavaara J, Viitala J (1999) Ultraviolet reflection of berries attracts foraging birds. A laboratory study with redwings (Turdus iliacus) and bilberries (Vaccinium myrtillus). P Roy Soc B-Biol Scie 266:21252129

Silvonen K, Top-Jensen M, Fibiger M (2014) Suomen päivä-ja yöperhoset - maastokäsikirja (A field guide to the butterflies and moths of Finland). Bugbook Publishing, Oestermarie, Denmark

Strauss SY, Rudgers JA, Lau JA, Irwin RE (2002) Direct and ecological costs of resistance to herbivory. Trends Ecol Evol17: 278-285

Tamura H, Yamagami A (1994) Antioxidative activity of monoacylated anthocyanins isolated from Muscat Bailey A grape. J Agr Food Chem 42:1612-1615

Thalmann C, Freise J, Heitland W, Bacher S (2003) Effects of defoliation by horse chestnut leafminer (Cameraria ohridella) on reproduction in Aesculus hippocastanum. Trees-Struct Funct 17: 383-388.

Tiitinen KM, Yang BR, Haraldsson GG, Jonsdottir S, Kallio HP (2006) Fast analysis of sugars, fruit acids, and vitamin C in sea buckthorn (Hippophae rhamnoides L.) varieties. J Agr Food Chem 54:2508-2513

Tolvanen A (1994) Differences in recovery between a deciduous and an evergreen ericaceous clonal dwarf shrub after simulated aboveground herbivory and belowground damage. Can J Bot 72: 853-859

Tolvanen A, Laine K (1997) Effects of reproduction and artificial herbivory on vegetative growth and resource levels in deciduous and evergreen dwarf shrubs. Can J Bot 75:656-666

Tolvanen A, Laine K, Pakonen T, Saari E, Havas P (1993). Aboveground growth-response of the bilberry ( Vaccinium myrtillus L.) to simulated herbivory. Flora 188:197-202

Tolvanen A, Laine K, Pakonen T, Saari E, Havas P (1994) Responses of harvesting intensity in a clonal dwarf shrub, the bilberry (Vaccinium myrtillus L.). Vegetatio 110:163-169

Ton J, D'Alessandro M, Jourdie V, Jakab G, Karlen D, Held M, Mauch-Mani B, Turlings TCJ (2007) Priming by airborne signals boosts direct and indirect resistance in maize. Plant J 49:16-26

Traveset A, Willson MF, Gaither JC (1995) Avoidance by birds of insect-infested fruits of Vaccinium ovalifolium. Oikos 73:381-386

Treadwell LW, Cuda JP (2007) Effects of defoliation on growth and reproduction of Brazilian peppertree (Schinus terebinthifolius). Weed Sci 55:137-142

Uleberg E, Rohloff J, Jaakola L, Trôst K, Junttila O, Häggman H, Martinussen I (2012) Effects of temperature and photoperiod on yield and chemical composition of northern and southern clones of bilberry (Vaccinium myrtillus L.). J Agr Food Chem 60:10406-10414 
van Lent J, Hernández-Barrios JC, Anten NPR, Martínez-Ramos M (2014) Defoliation effects on seed dispersal and seedling recruitment in a tropical rain forest understorey palm. J Ecol 102:709-720

Wang H, Cao GH, Prior RL (1997) Oxygen radical absorbing capacity of anthocyanins. J Agr Food Chem 45:304309

Wang SY, Camp MJ (2000) Temperatures after bloom affect plant growth and fruit quality of strawberry. Sci Hortic-Amsterdam 85:183-199

Wheelwright NT (1993) Fruit size in a tropical tree species- variation, preference by birds, and heritability. Vegetatio 108:163-174

Whitehead SR, Poveda K (2011) Herbivore-induced changes in fruit-frugivore interactions. J Ecol 99:964 -969

Wise MJ, Sacchi CF (1996) Impact of two specialist insect herbivores on reproduction of horse nettle, Solanum carolinense. Oecologia 108:328-337

Zangerl AR, Hamilton JG, Miller TJ, Crofts AR, Oxborough K, Berenbaum MR, de Lucia EH (2002) Impact of folivory on photosynthesis is greater than the sum of its holes. P Natl Acad Sci USA 99:1088-1091

Zheng J, Yang BR, Ruusunen V, Laaksonen O, Tahvonen R, Hellsten J, Kallio H (2012) Compositional differences of phenolic compounds between black currant (Ribes nigrum L.) cultivars and their response to latitude and weather conditions. J Agr Food Chem 60:6581-6593

Zheng W, Wang SY (2003) Oxygen radical absorbing capacity of phenolics in blueberries, cranberries, chokeberries, and lingonberries. J Agr Food Chem 51:502-509

Åkerström A, Jaakola L, Bång U, Jäderlund A (2010) Effects of latitude-related factors and geographical origin on anthocyanidin concentrations in fruits of Vaccinium myrtillus L. (bilberries). J Agr Food Chem 58:1193911945 
TABLE 1 Reference compounds used in the GC-FID analysis of sugars and organic acids. Superscript represents internal standards, and compounds without superscript are external standards.

\begin{tabular}{ll}
\hline Compounds & \multicolumn{1}{c}{ Company } \\
\hline sorbitol $^{\mathrm{i}}$ & Sigma-Aldrich, St. Louis, MO \\
tartaric acid $^{\mathrm{i}}$ & Merck, Darmstadt, Germany \\
ascorbic acid $_{\text {citric acid }}$ & VWR, Prolabo, Briare, France \\
sucrose & J.T.Baker, Deventer, Holland \\
malic acid & J.T.Baker, Deventer, Holland \\
quinic acid & Fluka Chemika, Buchs, Switzerland \\
glucose & Aldrich, Steinheim, Germany \\
fructose & Merck, Darmstadt, Germany \\
myo-inositol & Merck, Darmstadt, Germany \\
xylose & Fluka Chemie AG, Buchs, Switzerland \\
\hline
\end{tabular}


TABLE 2 Results of fixed explanatory factors from GLMM explaining the probability of ripening of berries

\begin{tabular}{|lcc|}
\hline Independent variables & $F_{d f}$ & $P$ \\
\hline Year & $67_{1,15.88}$ & $<0.01$ \\
Treatment (Plot type) & $7.28_{2,338.2}$ & $<0.01$ \\
Plot type & $1.01_{1,94.7}$ & 0.32 \\
Year $\times$ Plot type & $0.35_{1,94.7}$ & 0.56 \\
Year $\times$ Treatment (Plot type) & $6.32_{2,338.2}$ & $<0.01$ \\
\hline
\end{tabular}


TABLE 3 Results of fixed explanatory factors from GLMM on the probability for berries being foraged by frugivores

\begin{tabular}{|lcc|}
\hline Independent variables & $F_{d f}$ & $P$ \\
\hline Year & $0.08_{1,20.36}$ & 0.78 \\
Treatment (Plot type) & $2.96_{2,331.6}$ & 0.05 \\
Plot type & $3.06_{1,107.8}$ & 0.08 \\
Total number of ripened berries in a ramet & $4.69_{1,211.2}$ & 0.03 \\
Year $\times$ Plot type & $<0.01_{1,107.8}$ & 0.99 \\
Year $\times$ Treatment (Plot type) & $0.83_{2,331.1}$ & 0.44 \\
\hline
\end{tabular}


TABLE 4 Results of fixed explanatory factors from GLMM on the total concentrations of anthocyanins, sugars and organic acids

\begin{tabular}{|l|cc|cc|cc|}
\hline & \multicolumn{2}{|c|}{ Anthocyanins } & \multicolumn{2}{|c|}{ Sugars } & \multicolumn{2}{c|}{ Organic acids } \\
Independent variables & $F_{d f}$ & $P$ & $F_{\mathrm{df}}$ & $P$ & $F_{d f}$ & $P$ \\
\hline Treatment (plot type) & $0.52_{2,51.8}$ & 0.60 & $1.43_{2,46.51}$ & 0.25 & $1.55_{2,47.98}$ & 0.22 \\
\hline Plot type & $0.02_{1,51.11}$ & 0.88 & $1.29_{1,47.37}$ & 0.26 & $0.11_{1,48.69}$ & 0.74 \\
\hline Year & $0.42_{1,16.71}$ & 0.53 & $3.53_{1,16.45}$ & 0.08 & $0.63_{1,18.48}$ & 0.44 \\
\hline Plot typex Year & $0.67_{1,51.11}$ & 0.42 & $4.32_{1,47.37}$ & 0.04 & $2.84_{1,48,69}$ & 0.10 \\
\hline $\begin{array}{l}\text { Year } \times \text { Treatment (Plot } \\
\text { type) }\end{array}$ & $0.28_{2,51.8}$ & 0.76 & $1.48_{2,46.51}$ & 0.24 & $1_{2.47 .98}$ & 0.30 \\
\hline
\end{tabular}


TABLE 5 Estimated marginal means with $95 \%$ confidence intervals for total concentrations of anthocyanins, sugars and organic acids of bilberries (mg/g DW) in different treatments. In total, 77 bilberry samples were used.

\begin{tabular}{|lccc|}
\hline & Anthocyanins & Sugars & Organic acids \\
\cline { 2 - 4 } & $\begin{array}{c}\text { Mean [95\% CIs] } \\
\text { (n) }\end{array}$ & $\begin{array}{c}\text { Mean [95\% CIs] } \\
\text { (n) }\end{array}$ & $\begin{array}{c}\text { Mean [95 \% CIs] } \\
\text { (n) }\end{array}$ \\
\cline { 2 - 4 } Control & $21.1[18.0$ to 24.8$]$ & $547.1[483.2$ to 611.0$]$ & $116.0[100.9$ to 131.1$]$ \\
& $(19)$ & $(19)$ & $(19)$ \\
Methodological control & $23.1[19.8$ to 27.1$]$ & $579.7[515.8$ to 643.5$]$ & $129.6[114.5$ to 144.7$]$ \\
& $(20)$ & $(19)$ & $(19)$ \\
Larval-defoliation & $22.7[19.4$ to 26.5$]$ & $564.4[496.9$ to 632.0$]$ & $125.8[109.9$ to 141.7$]$ \\
& $(20)$ & $(17)$ & $(17)$ \\
Rhizome signalling & $21.0[17.7$ to 24.8$]$ & $633.6[561.8$ to 705.4$]$ & $115.1[98.2$ to 131.9$]$ \\
& $(18)$ & $(16)$ & $(16)$ \\
\hline
\end{tabular}


Fig. 1 A schematic presentation of the experimental design where a represents control plots and $\mathbf{b}$ represents herbivore treatment plots. The non-bagged bilberry ramets (1) in control plots represent controls and ramets with empty mesh bags (2) represent methodological controls. In herbivore treatment plots, non-bagged ramets (3) represent rhizome signalling treatment and ramets with mesh bags containing larvae (4) represent larval-defoliated ramets 
Fig. 2 Estimated marginal means for the probability for ripening in different treatments. Values depict significant year by treatment (nested within plot type) interaction effect of the GLMM described in the text. Error bars represent $95 \%$ confidence intervals 
Fig. 3 Estimated marginal means for the probability of berries being foraged in different treatment (nested within plot type). Error bars represent $95 \%$ confidence intervals 
Fig. 4 Estimated marginal means for the total concentration of sugars in different plot types in both study years. Values depict significant year by plot type interaction effect of the GLMM described in the text. Error bars represent $95 \%$ confidence intervals 


\title{
Supplementary Information
}

\author{
Journal of Chemical Ecology
}

\section{EFFECTS OF INSECT HERBIVORY ON BILBERRY PRODUCTION AND REMOVAL OF BERRIES BY FRUGIVORES}

\author{
TUULI-MARJAANA KOSKI' ${ }^{* 1}$, MARIKA KALPIO ${ }^{2}$, TONI LAAKSONEN ${ }^{1}$, PÄIVI M. SIRKIÄ ${ }^{1,3}$, HEIKKI P. KALLIO ${ }^{2,4}$, \\ BAORU YANG ${ }^{2}$, KAISA M. LINDERBORG ${ }^{2}$, TERO KLEMOLA ${ }^{1}$ \\ ${ }^{I}$ Section of Ecology, Department of Biology, University of Turku, FI-20014, Turku, Finland \\ ${ }^{2}$ Section of Food Chemistry and Food Development, Department of Biochemistry, University of Turku, FI-20014, Turku, \\ Finland \\ ${ }^{3}$ Finnish Natural History Museum, Zoology Unit, University of Helsinki, FI-00014, Finland \\ ${ }^{4}$ Centre for Environmental Research, Kevo Subarctic Research Institute, University of Turku, FI-20014, Turku, Finland
}

Corresponding author:

Tuuli-Marjaana Koski; tmhkos@utu.fi

Section of Ecology, Department of Biology, University of Turku, FI-20014, Turku, Finland

Tel. $+358(0) 407719168$ 


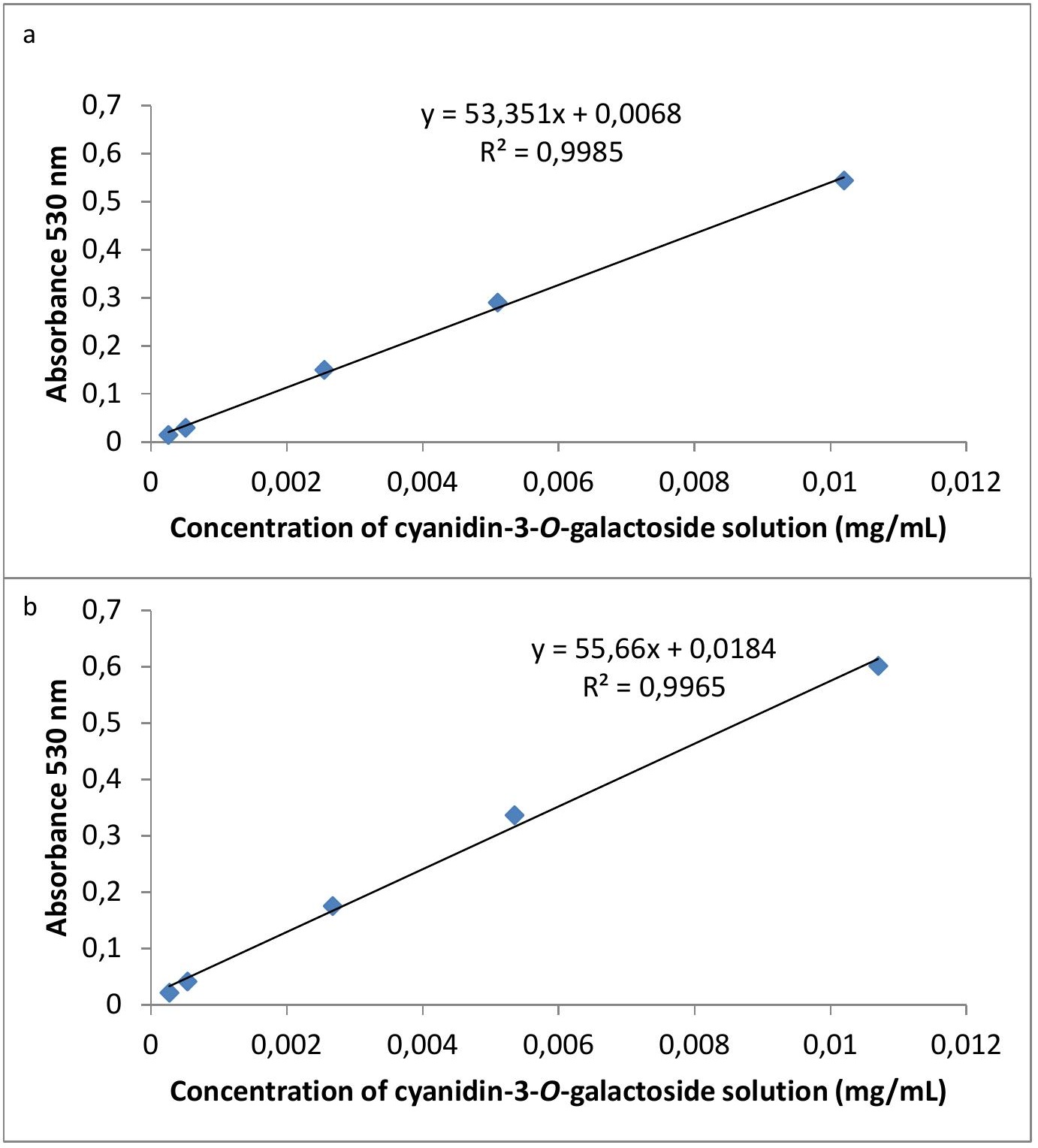

Fig. S1 The standard curves for calculating the amount of total anthocyanins as cyanidin-3-O-galactoside equivalents, a) for 2013 samples and b) for 2014 samples. 

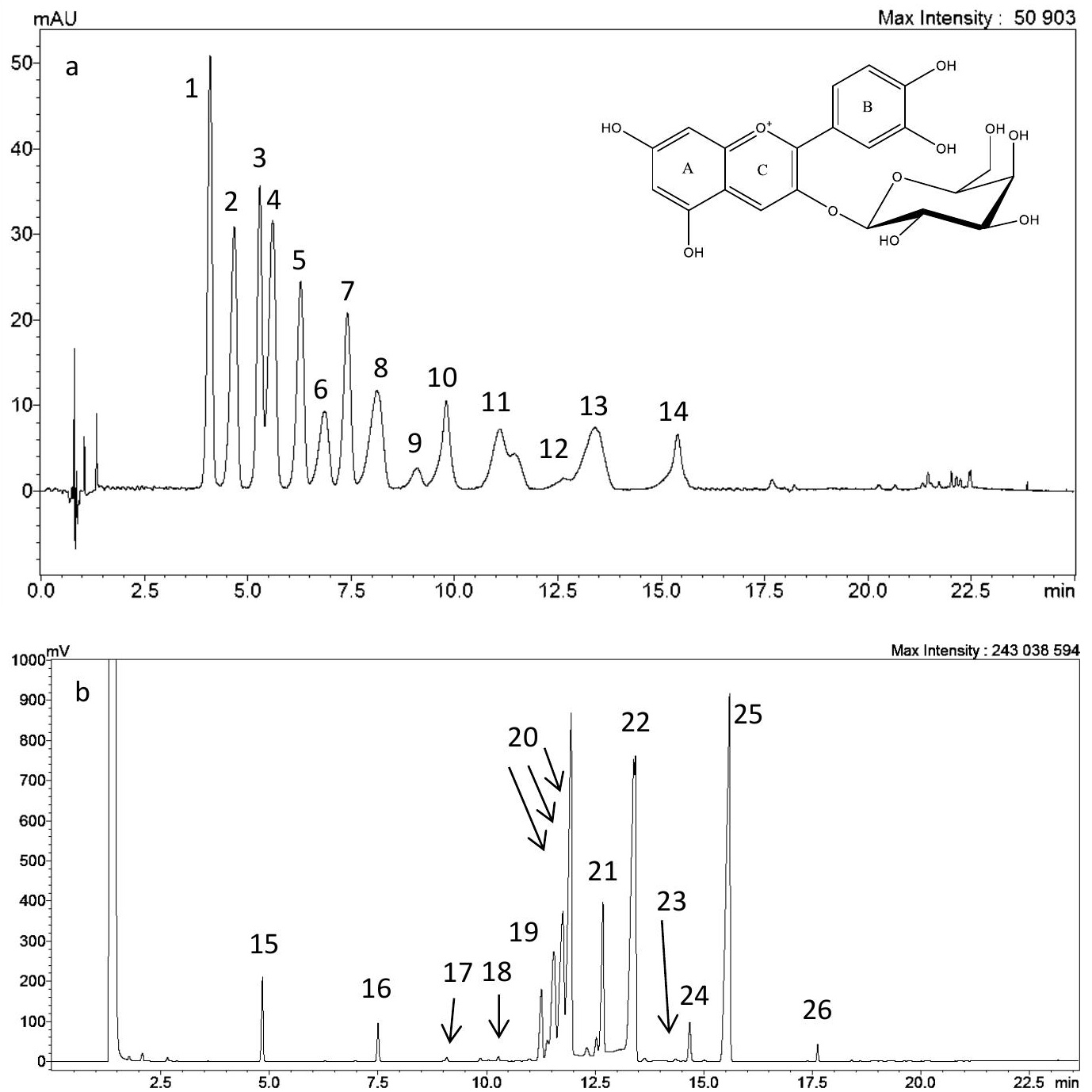

Fig. S2 a) An example UHPLC-DAD chromatogram of anthocyanins $(520 \mathrm{~nm})$ in bilberry (Vaccinium myrtillus). 1 delphinidin-3-O-galactoside, 2 delphinidin-3-O-glucoside, 3 cyanidin-3-O-galactoside, 4 delphinidin-3-Oarabinoside, 5 cyanidin-3- $O$-glucoside, 6 petunidin-3- $O$-galactoside, 7 cyanidin-3- $O$-arabinoside, 8 petunidin-3- $O$ glucoside, 9 peonidin-3- $O$-galactoside, 10 petunidin-3- $O$-arabinoside, 11 peonidin-3- $O$-glucoside + malvidin-3- $O$ galactoside, 12 peonidin-3- $O$-arabinoside, 13 malvidin-3- $O$-glucoside, 14 malvidin-3- $O$-arabinoside.

Anthocyanins occurring in nature contain several anthocyanidins (three ring structure of aglycone A, B, C). Usually, there is a sugar moiety attached to the aglycone forming anthocyanin (anthocyanidin glycoside). Example of anthocyanin structure: cyanidin-3-O-galactoside.

b) An example GC-FID chromatogram of TMS derivatives of the sugars and acids of bilberry (Vaccinium myrtillus). 15 malic acid, 16 tartaric acid (ISTD), 17 xylose $\alpha / \beta$-anomer, 18 xylose $\alpha / \beta$-anomer, 19 citric acid, 20 $\alpha$-D-fructofuranose, $\beta$-D-fructofuranose, $\beta$-D-fructopyranose, 21 quinic acid, $22 \alpha$-D-glucopyranose, 23 ascorbic acid, 24 sorbitol (ISTD), $25 \beta$-D-glucopyranose, 26 myo-inositol. 

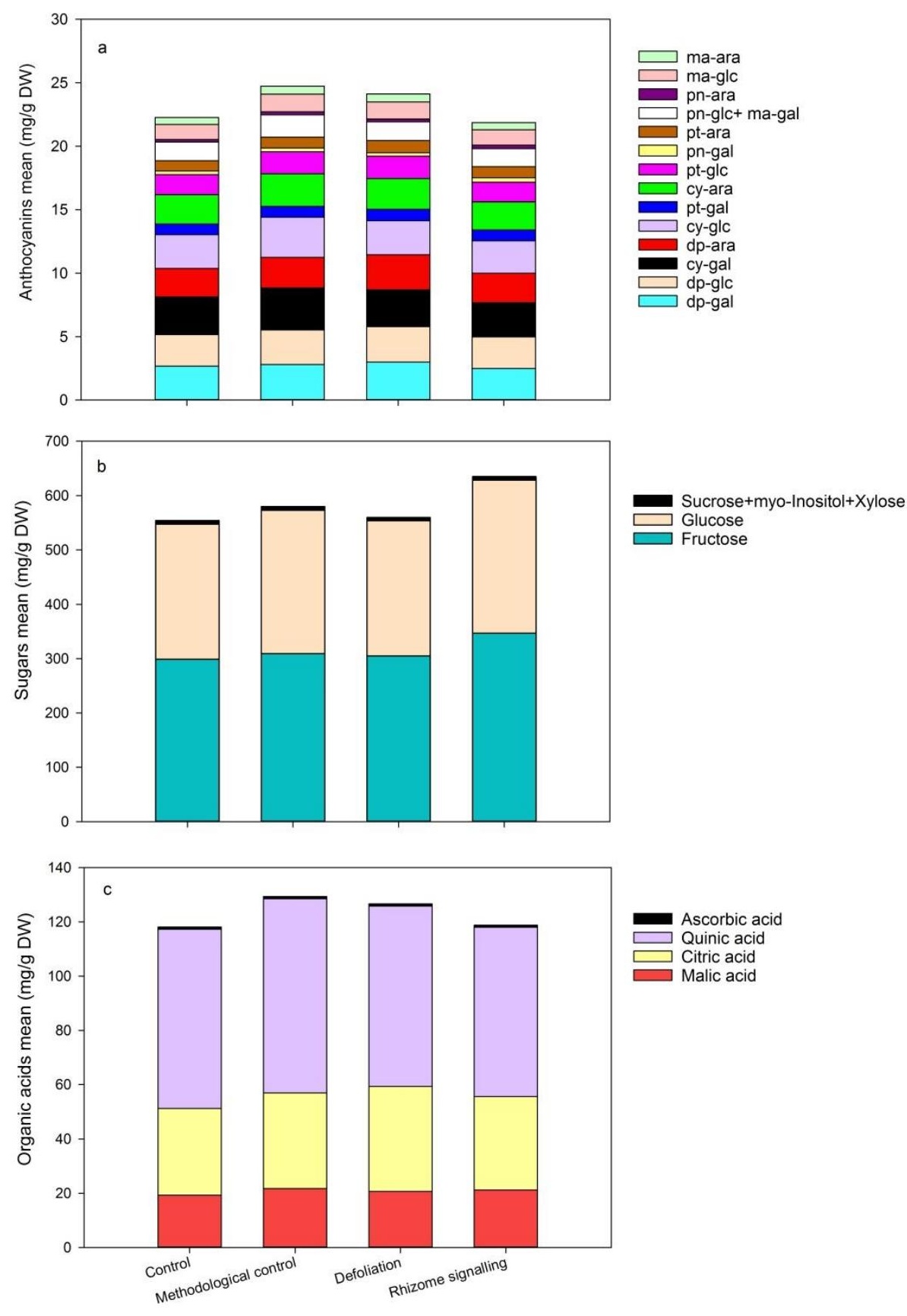

Fig S3 a) Proportions of anthocyanins b) sugars and c) organic acids in different treatments when the two study years were combined. $\mathrm{N}$ = 19 control, 20 methodological control, 20 defoliation and 18 rhizome signaling, respectively. Abbreviations of anthocyanin compounds; $d p$-gal: delphinidin-3-O-galactoside, $d p$ - $g l c$ : delphinidin3-O-glucoside, $c y$-gal: cyanidin-3-O-galactoside, $d p$-ara: delphinidin-3- $O$-arabinoside, $c y$-glc: cyanidin-3-Oglucoside, $p t$-gal: petunidin-3- $O$-galactoside, $c y$-ara: cyanidin-3- $O$-arabinoside, $p t$-glc: petunidin-3-O-glucoside, pn-gal: peonidin-3-O-galactoside, $p t$-ara: petunidin-3-O-arabinoside, $p n$-glc + ma-gal: peonidin-3-O-glucoside + malvidin-3-O-galactoside, $p n$-ara: peonidin-3-O-arabinoside, $m a$-glc: malvidin-3-O-glucoside, ma-ara: malvidin3-O-arabinoside. 
Table S1 Results from GLMM, of fixed explanatory factors explaining concentration of (mg/g DW) individual anthocyanins, sugars and acid compounds identified from bilberry samples. Statistically significant differences are indicated with bold. ${ }^{\text {Log }}$ indicates lognormal distribution used in the GLMM analysis.

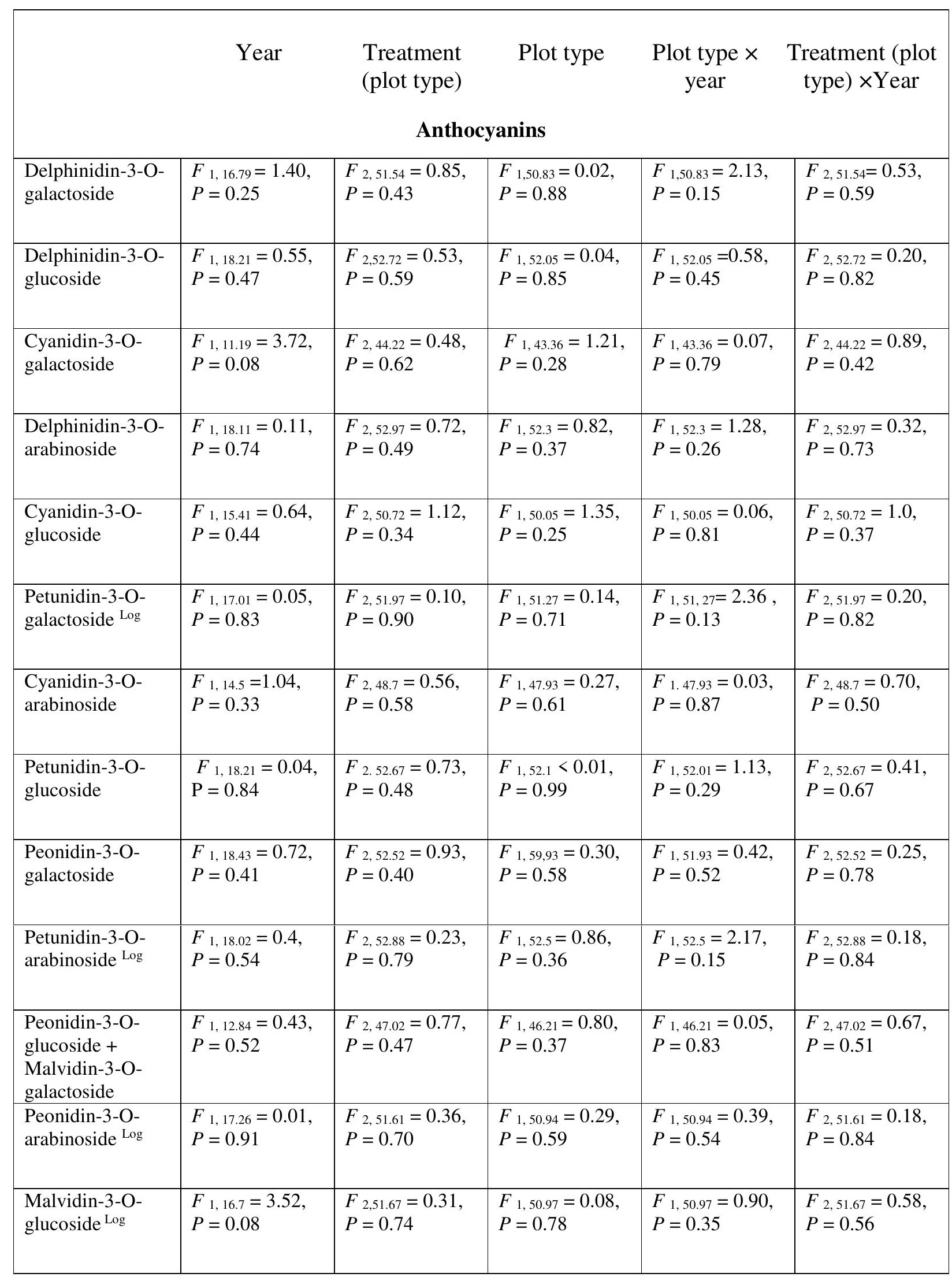




\begin{tabular}{|c|c|c|c|c|c|}
\hline $\begin{array}{l}\text { Malvidin-3-O- } \\
\text { arabinoside }^{\text {Log }}\end{array}$ & $\begin{array}{l}F_{1,17.32}=0.07 \\
P=0.79\end{array}$ & $\begin{array}{l}F_{2,51.64}=0.54 \\
P=0.59\end{array}$ & $\begin{array}{l}F_{150.99}=0.68 \\
P=0.41\end{array}$ & $\begin{array}{l}F_{1,50.99}=0.19 \\
P=0.66\end{array}$ & $\begin{array}{l}F_{2,51.64}=0.56, \\
P=0.57\end{array}$ \\
\hline \multicolumn{6}{|c|}{ Sugars } \\
\hline Fructose & $\begin{array}{l}F_{1,16.78}=1.30 \\
P=0.27\end{array}$ & $\begin{array}{l}F_{2,46.75}=1.24 \\
P=0.30\end{array}$ & $\begin{array}{l}F_{1,47.59}=1.84 \\
P=0.18\end{array}$ & $\begin{array}{l}F_{1,47.59}=3.06 \\
P=0.09\end{array}$ & $\begin{array}{l}F_{2,46.75}=1.38, \\
P=0.26\end{array}$ \\
\hline Glucose & $\begin{array}{l}F_{1,16.19}=8.60, \\
P=\mathbf{0 . 0 1}\end{array}$ & $\begin{array}{l}F_{2,46.61}=1.50 \\
P=0.23\end{array}$ & $\begin{array}{l}F_{1,47.54}=0.56 \\
P=0.46\end{array}$ & $\begin{array}{l}F_{1,47.54}=5.37 \\
P=\mathbf{0 . 0 2}\end{array}$ & $\begin{array}{l}F_{2,46.61}=1.33, \\
P=0.27\end{array}$ \\
\hline Sucrose + Xylose & $\begin{array}{l}F_{1,15.68}=26.01 \\
P<\mathbf{0 . 0 1}\end{array}$ & $\begin{array}{l}F_{2,48.13}=4.27 \\
P=\mathbf{0 . 0 2}\end{array}$ & $\begin{array}{l}F_{1,49.14}=0.39 \\
P=0.53\end{array}$ & $\begin{array}{l}F_{1,49.14}=6.26 \\
P=\mathbf{0 . 0 2}\end{array}$ & $\begin{array}{l}F_{2,48.13}=3.40, \\
P=\mathbf{0 . 0 4}\end{array}$ \\
\hline Myo-Inositol & $\begin{array}{l}F_{1,17.77}=0.04, \\
P=0.83\end{array}$ & $\begin{array}{l}F_{2,47.74}=1.34 \\
P=0.27\end{array}$ & $\begin{array}{l}F_{1,48.56}=0.40 \\
P=0.53\end{array}$ & $\begin{array}{l}F_{1,48.56}=0.01 \\
P=0.91\end{array}$ & $\begin{array}{l}F_{2,47.74}=2.42, \\
P=0.10\end{array}$ \\
\hline \multicolumn{6}{|c|}{ Organic acids } \\
\hline Malic acid ${ }^{\log }$ & $\begin{array}{l}F_{1,17.94}=6.05 \\
P=\mathbf{0 . 0 2}\end{array}$ & $\begin{array}{l}F_{2,47.2}=0.55, \\
P=0.58\end{array}$ & $\begin{array}{l}F_{1,47.85}=0.20 \\
P=0.66\end{array}$ & $\begin{array}{l}F_{1,47.85}=0.02 \\
P=0.90\end{array}$ & $\begin{array}{l}F_{2,47.2}=2.82, \\
P=0.07\end{array}$ \\
\hline Citric acid & $\begin{array}{l}F_{1,15.45}=2.49 \\
P=0.14\end{array}$ & $\begin{array}{l}F_{2,45.63}=0.93 \\
P=0.40\end{array}$ & $\begin{array}{l}\mathrm{F}_{1,46.56}=0.68 \\
P=0.41\end{array}$ & $\begin{array}{l}F_{1,46.56}=0.38 \\
P=0.54\end{array}$ & $\begin{array}{l}F_{2,45.63}=0.73, \\
P=0.49\end{array}$ \\
\hline Quinic acid & $\begin{array}{l}F_{1,19.13}=0.60 \\
P=0.45\end{array}$ & $\begin{array}{l}F_{2,48.22}=1.23 \\
P=0.30\end{array}$ & $\begin{array}{l}F_{1,48.84}=1.39 \\
P=0.24\end{array}$ & $\begin{array}{l}F_{1,48.84}=5.23 \\
P=\mathbf{0 . 0 3}\end{array}$ & $\begin{array}{l}F_{2,48.22}=0.81, \\
P=0.45\end{array}$ \\
\hline Ascorbic acid & $\begin{array}{l}F_{1,15.72}=0.10 \\
P=0.76\end{array}$ & $\begin{array}{l}F_{2,46.97}=0.30 \\
P=0.74\end{array}$ & $\begin{array}{l}F_{1,48}=0.07 \\
P=0.79\end{array}$ & $\begin{array}{l}F_{1,48}=0.37 \\
P=0.54\end{array}$ & $\begin{array}{l}F_{2,46.97}=2.17, \\
P=0.13\end{array}$ \\
\hline
\end{tabular}



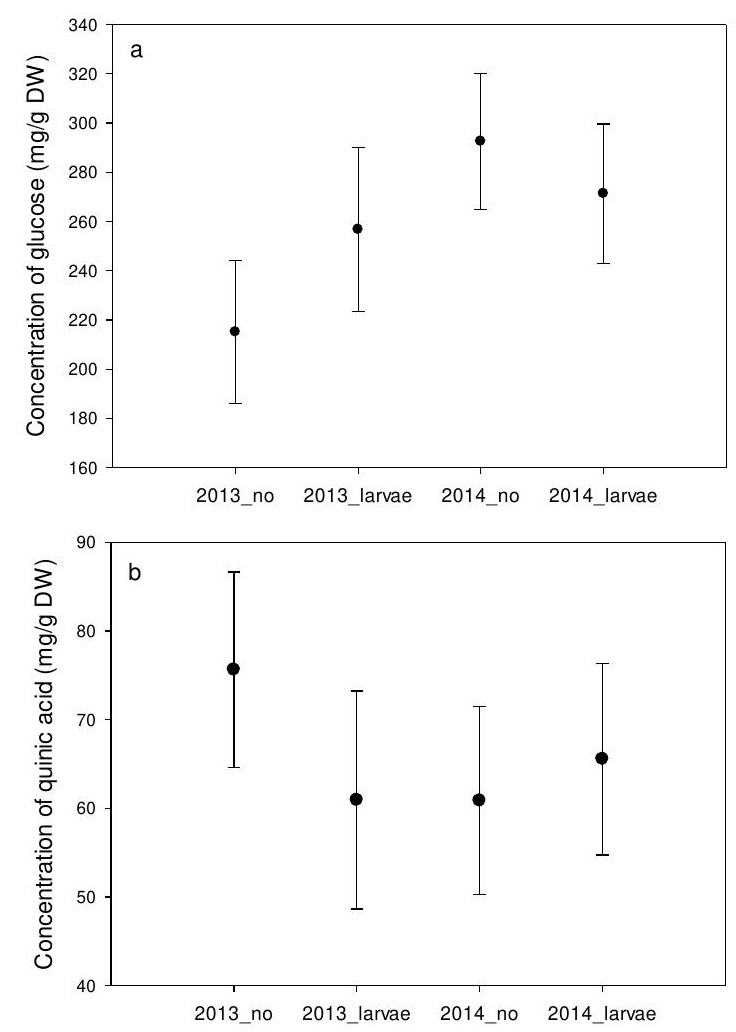

Fig S4. Estimated marginal means and $95 \%$ confidence intervals for the concentration of a) glucose and b) quinic acid. Values depict significant year by plot type interaction effect of the GLMM described in the text. 


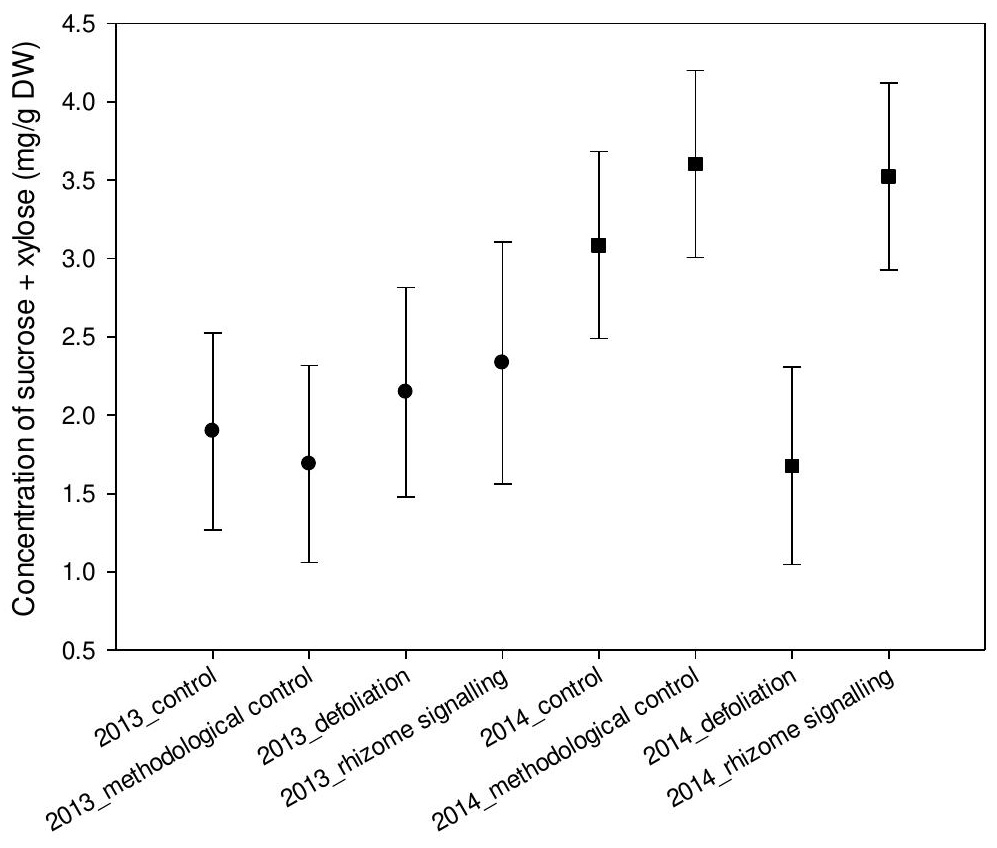

Fig S5 Estimated marginal means and $95 \%$ confidence intervals for the summed concentration of sucrose and xylose. Values depict significant year by treatment (plot type) interaction effect of the GLMM described in the text. 